\title{
Caffeoyl arbutin and related compounds from the buds of Vaccinium dunalianum
}

Ping Zhao,, ${ }^{\mathrm{a}, 1}$ Takashi Tanaka, ${ }^{\mathrm{a},{ }^{*}}$ Keisuke Hirabayashi, ${ }^{\mathrm{a}}$ Ying-Jun Zhang, ${ }^{\mathrm{b}}$ Chong-Ren Yang, ${ }^{\mathrm{b}}$ Isao $\mathrm{Kouno}^{\mathrm{a}, *}$

${ }^{a}$ Laboratory of Natural Product Chemistry, Graduate School of Biomedical Sciences, Nagasaki University, Bunkyo Machi 1-14, Nagasaki 852-8521, Japan

${ }^{\mathrm{b}}$ State Key Laboratory of Phytochemistry and Plant Resources in West China, Kunming Institute of Botany, Chinese Academy of Sciences, Kunming 650204, China

\footnotetext{
* Corresponding author. Tel.: + 81-95-819-2433, Fax: +81-95-819-2477.

E-mail address:t-tanaka@nagasaki-u.ac.jp (T. Tanaka)

${ }^{1}$ Present address: Laboratory of Cell Biotechnology, Biotechnology Research Center, The University of Tokyo, 1-1-1 Yayoi, Bunkyo-ku, 113-8657, Tokyo, Japan.
} 


\begin{abstract}
Dunalianosides A-I (1-9), esters of arbutin and related phenolic glucosides, were isolated from the buds of Vaccinium dunalianum Wight (Ericaceae) together with 20 known compounds, and their structures were established on the basis of 1- and 2D NMR spectroscopic evidence. Dunalianosides $\mathrm{F}-\mathrm{H}$ were dimers of p-hydroxyphenyl 6-O-trans-caffeoyl- $\beta$-D-glucopyranoside (10), which was obtained in extraordinary high yield ( $22 \%$ of the dry weight), and dunalianoside I (9) was found to be a conjugate of arbutin with an iridoid glucoside.
\end{abstract}

Keywords: Vaccinium dunalianum; Ericaceae; Caffeoyl arbutin; Dunalianoside; p-Hydroxyphenyl 6-O-trans-caffeoyl- $\beta$-D-glucopyranoside. 


\section{Introduction}

Vaccinium dunalianum Wight (Ericaceae) is an evergreen perennial shrub distributed in the Southwest of China, Myanmar and Vietnam. The local people of its growing area in China use the leaf of this plant as a folk medicine for the treatment of articular rheumatism, and also substitute its dried buds for tea to prepare a traditional folk beverage. It is well known that the Vaccinium species are rich sources of naturally occurring dietary phenolics, such as flavonoids, anthocyanins, proanthocyanidins and other phenolic compounds (Prior et al., 1998; Moyer, et al., 2002; Taruscio et al., 2004), which have been identified as antioxidants, with the potential to prevent oxidative damage caused by reactive oxygen species. However, no chemical investigation has been reported on the title plant. In continuing studies on phenolic constituents from medicinal plants, the occurrence of significant amounts of phenolics in the buds of this plant has been suggested by TLC analysis in our preliminary analysis. Further study of phenolics in the buds of this plant has led to the isolation of eight novel caffeoyl derivatives of arbutin, namely dunalianosides A-H (1-8), and a new conjugate of arbutin with an iridoidal glycoside, dunalianoside I (9), together with 20 known compounds (10-29). Of these, $p$-hydroxyphenyl 6-O-trans-caffeoyl- $\beta$-D-glucopyranoside (10) was isolated in $22 \%$ yield from the dried buds. This study investigated the isolation and structural elucidation of these compounds. 


\section{Results and Discussion}

A $60 \%$ aqueous acetone extract of the air-dried buds of $V$. dunalianum was first defatted by partitioning with ether, and then the aqueous layer was concentrated to yield large amounts of the off-white crystalliferous solids. The solids were collected by filtration and re-crystallized to yield $p$-hydroxyphenyl 6-O-trans-caffeoyl- $\beta$-D-glucopyranoside (robustaside B, 10) $(22 \%$ of the dry weight) (Machida et al., 1991). The filtrate was concentrated, and the residue was chromatographed successively on Diaion HP-20, Sephadex LH-20, MCI gel CHP20P, Chromatorex ODS, Toyopearl HW-40F, and silica gel to give dunalianosides A-I (1-9), along with 19 known compounds. By comparisons of the physical and spectral data with those of previously reported spectral data and direct comparison with authentic standards, the known compounds, in addition to $\mathbf{1 0}$, were characterized as p-hydroxyphenyl 6-O-trans-caffeoyl- $\beta$-D-glucopyranoside (arbutin, 11) (Dommisse et al., 1986), p-hydroxyphenyl 6-O-acetyl- $\beta$-D-glucopyranoside (pyroside, 12) (Machida and Kikuchi, 1993), $\quad$-hydroxyphenyl 6-O-(4- $\beta$-D-glucopyranosyl-trans-caffeoyl)- $\beta$-D-glucopyranoside (robustaside C, 13) (Ahmed et al., 2000), p-hydroxyphenyl 6-O-trans-coumaroyl- $\beta$-D-glucopyranoside (robustaside A, 14) (Machida and Kikuchi, 1993), monotropein (15) (Jensen et al., 2002) and scandoside (16) (Bailleul et al., 1977), benzyl alcohol $\beta$-D-glucopyranoside (17) (Kitajima et al., 1998), icariside $F_{2}(\mathbf{1 8})$ (Ono et al., 1996), parasorboside (19), methyl (3S, 5S)-5-hydroxy-3-( $\beta$-D-glucopyranosyl)-hexanoate (20) 
(Numata et al., 1990), 6-O-trans-caffeoyl-D-glucopyranose (21) (Shimomura et al., 1987), ferulic acid 4-O- $\beta$-D-glucoside (22) (Shoyama et al., 1987), kaempferol 3-O- $\beta$-D-glucopyranoside (23) (Vvedenskaya et al., 2004), caffeic acid (24), chlorogenic acid (25), 3-O-feruloylquinic acid (26) (Morishita et al., 1984), 3-O-p-coumarylquinic acid (27), (-)-shikimic acid (28) (Wada et al., 1992), and tryptophan (29).

Compound 1 was obtained as an off-white amorphous powder, and its molecular formula $\mathrm{C}_{21} \mathrm{H}_{22} \mathrm{O}_{10}$ was confirmed by the positive HR-FAB-MS $[\mathrm{m} / \mathrm{z} 434.1234 \text { ([M] }]^{+}$), calcd. 434.1213] and the number of ${ }^{13} \mathrm{C}$ NMR spectral signals. The ${ }^{1} \mathrm{H}$ and ${ }^{13} \mathrm{C}$ NMR spectra closely resembled those of $\mathbf{1 0}$ (Machida et al., 1991), except for the signals due to the caffeoyl moiety. The olefin proton signals of 1 were observed at $\delta 5.77$ and 6.82 (each $\mathrm{d}, J=12.9 \mathrm{~Hz}$ ) (Table 1), which were resonated at the upper field compared to those of $\mathbf{1 0}(\Delta \delta 0.51,0.7$, respectively), and the coupling constant was smaller $(\mathbf{1 0}: J=15.6 \mathrm{~Hz})$. This observation indicated that the geometry of the double bond in the caffeoyl moiety of $\mathbf{1}$ was the cis form. The chemical shifts of glucose H-6' $[\delta 4.49(\mathrm{dd}, J=11.7,1.8 \mathrm{~Hz})$ and $4.30(\mathrm{dd}, J=11.7,6.6$ $\mathrm{Hz})]$, and C-6' ( $\delta 64.3$ ) confirmed the location of the cis-caffeoyl moiety at this position. On the basis of these spectral data, compound $\mathbf{1}$ was determined to be p-hydroxyphenyl 6'-O-cis-caffeoyl- $\beta$-D-glucopyranoside, and named dunalianoside A.

Compound 2 was obtained as an off-white amorphous powder. Its molecular formula was deduced to be $\mathrm{C}_{21} \mathrm{H}_{22} \mathrm{O}_{11}$ on the basis of the positive HR-FAB-MS [m/z $451.1213\left([\mathrm{M}+\mathrm{H}]^{+}\right.$, 
calcd. 451.1240)]. The ${ }^{1} \mathrm{H}$ and ${ }^{13} \mathrm{C}$ NMR spectral data of 2 were closely related to those of $\mathbf{1 0}$, which indicated the presence of a 6-O-caffeoyl- $\beta$-glucopyranoside residue in the molecule. However, instead of the aromatic AA'BB' coupling system attributed to the $p$-substituted phenyl moiety in 10, an ABX coupling system [ $\delta 6.27(1 \mathrm{H}, \mathrm{d}, J=2.7 \mathrm{~Hz}, \mathrm{H}-3), 6.09(1 \mathrm{H}$, dd, $J=8.7,2.7 \mathrm{~Hz}, \mathrm{H}-5), 6.93(1 \mathrm{H}, \mathrm{d}, J=8.7 \mathrm{~Hz}, \mathrm{H}-6)]$ (Table 1) was observed in the ${ }^{1} \mathrm{H}$ NMR spectrum of 2. Furthermore, the ${ }^{13} \mathrm{C}$ NMR spectrum of 2 (Table 1) showed signals arising from a 1, 2, 4-trisubstituted benzene ring (C-1-C-6). These findings indicated that 2 had an additional hydroxyl group in the phenyl moiety. The location of the glucose moiety and two hydroxyl groups in the aglycone moiety was confirmed by the NOESY experiment, which showed correlations between the glucose anomeric proton $\left[\delta 4.54\left(1 \mathrm{H}, \mathrm{d}, J=7.8 \mathrm{~Hz}, \mathrm{H}-1^{\prime}\right)\right]$ and aglycone H-6 ( $\delta$ 6.93), and between H-5 ( $\delta 6.09)$ and H-6 (Fig. 1). Therefore, compound 2 was characterized as 2,4-dihydroxyphenyl 1-O-(6'-O-trans-caffeoyl)- $\beta$-D-glucopyranoside, and named dunalianoside $\mathrm{B}$.

Compound 3 was obtained as an off-white amorphous powder. From the result of positive HR-FAB-MS [m/z $451.1224\left([\mathrm{M}+\mathrm{H}]^{+}\right.$, calcd. 451.1240)], its molecular formula was deduced to be $\mathrm{C}_{21} \mathrm{H}_{22} \mathrm{O}_{11}$, which was identical to that of 2 . The ${ }^{1} \mathrm{H}$ NMR spectrum of $\mathbf{3}$ (Table 1) was also related to that of $\mathbf{2}$ and showed signals due to two sets of ABX-aromatic, trans-olefinic, and sugar proton signals. A difference in the chemical shifts was observed in one of the ABX-spin systems due to presence of a trisubstituted benzene moiety. The substitution on the 
benzene ring was determined by the NOESY experiment, which showed correlations between the anomeric proton at $\delta 4.73$ and both H-2 $(\delta 6.64)$ and H-6 $(\delta 6.46)$, and between H-6 and H-5 ( $\delta$ 6.63) (Fig. 1). Therefore, compound 3 was established as 3,4-dihydroxyphenyl 1-O-(6'-O-trans-caffeoyl)- $\beta$-D-glucopyranoside, and named dunalianoside C.

Compound 4 was obtained as an off-white amorphous powder, and had a molecular formula $\mathrm{C}_{22} \mathrm{H}_{24} \mathrm{O}_{11}$, which was deduced from the positive HR-FAB-MS [m/z 464.1320 ([M] $]^{+}$), calcd. 464.1318]. The ${ }^{1} \mathrm{H}$ and ${ }^{13} \mathrm{C}$ NMR spectral data of $\mathbf{4}$ were very similar to those of $\mathbf{3}$ (Table 1), except for appearance of signals due to a methoxy group $\left[\delta_{\mathrm{H}} 3.74(3 \mathrm{H}, \mathrm{s}), \delta_{\mathrm{c}} 56.4\right]$. The NOESY spectrum revealed the location of glucose at C-1 and the methoxy group at C-3, which showed correlations between the anomeric proton at $\delta 4.70(\mathrm{~d}, J=7.0 \mathrm{~Hz})$ and both H-2 $[\delta 6.70(\mathrm{~d}, J=1.8 \mathrm{~Hz})]$ and H-6 $[\delta 6.53(\mathrm{dd}, J=8.8,1.8 \mathrm{~Hz})]$, and between H-2 and the methoxy protons (Fig. 1). Therefore, compound 4 was established as 3-methoxy-4-hydroxyphenyl 1-O-(6'-O-trans-caffeoyl)- $\beta$-D-glucopyranoside, and named dunalianoside D.

Compound 5 was obtained as an off-white amorphous powder. Its molecular formula was deduced to be $\mathrm{C}_{23} \mathrm{H}_{24} \mathrm{O}_{11}$ on the basis of the positive HR-FAB-MS [m/z $476.1303\left([\mathrm{M}]^{+}\right)$, calcd. 476.1308]. From the ${ }^{1} \mathrm{H},{ }^{13} \mathrm{C}$ NMR and ${ }^{1} \mathrm{H}-{ }^{1} \mathrm{H}$ COSY spectral data (Table 1, Fig. 1), occurrence of an arbutin moiety, along with a trans-caffeoyl and an acetyl [ $\delta 2.10(s)]$ group, was easily deduced. In addition, the down field shifts of glucose $\mathrm{H}-4$ ' [ $\delta 4.90(1 \mathrm{H}, \mathrm{t}, J=9.5$ 
$\mathrm{Hz})]$ and $\mathrm{H}_{2}-6^{\prime}$ protons [ $\left.\delta 4.27(1 \mathrm{H}, \mathrm{dd}, J=12.5,5.5 \mathrm{~Hz}), 4.24(1 \mathrm{H}, \mathrm{dd}, J=12.5,9.5 \mathrm{~Hz})\right]$ indicated acylation of hydroxyl groups at these positions. The locations of the caffeoyl and acetyl groups on glucose core was determined by heteronuclear multiple bond coherence (HMBC), which showed a long-range $\mathrm{H}-\mathrm{C}$ correlation of glucose $\mathrm{H}_{2}-6$ ' with a carboxyl carbon $(\delta 168.7)$ of the caffeoyl group, and glucose H-4' with the carboxyl carbon $(\delta 172.1)$ of the acetyl group (Fig. 1). On the basis of the spectral evidence, compound 5 was characterized as $\quad p$-hydroxyphenyl 4'-O-acetyl-6'-O-trans-caffeoyl- $\beta$-D-glucopyranoside, and named dunalianoside $\mathrm{E}$.

Compounds 6 and 7, named as dunalianosides F and G, showed the same $R f$ value on silica gel TLC and similar chromatographic behavior during separation procedure. The final separation of these compounds was achieved by Toyopearl HW-40F column chromatography. The HR-FAB MS spectra of $6\left[\mathrm{~m} / \mathrm{z}, 866.2231\left([\mathrm{M}]^{+}\right)\right.$, calcd. 866.2269] and $7[\mathrm{~m} / \mathrm{z}, 867.2394$ $\left([\mathrm{M}+\mathrm{H}]^{+}\right)$, calcd. 867.2347] established the same molecular formula $\mathrm{C}_{42} \mathrm{H}_{42} \mathrm{O}_{20}$ for these compounds. The ${ }^{1} \mathrm{H}$ and ${ }^{13} \mathrm{C}$ NMR spectra of 6 and 7 were almost indistinguishable from each other, which indicated their structural similarity.

The ${ }^{1} \mathrm{H}$ NMR spectrum of compound 6 (Table 2) showed two sets of AA'BB'-aromatic doublets (H-2", 6", H-3", 5" and H-2'"', 6"'", H-3'"', H-5'"')] and two anomeric doublets (H-1"') and H-1"'"'). These signals were attributable to two arbutin moieties. In addition, a set of ABX-signal (H-2, H-5 and H-6)] and a pair of meta-coupled signals (H-2' and H-6') were 
observed in the aromatic region, which were assignable to the discrete sets of protons of the $1,3,4-$ and 1,3,4,5-substituted phenyl units, respectively. Also observed were two doublets $(J=$ 16.0 Hz) that arose from a pair of trans-olefinic protons, and two vicinally located methine protons (d each, $J=8.0 \mathrm{~Hz}$ ) that were assigned to the protons of the dihydrobenzofuran skeleton in 6. The dihydrobenzofuran skeleton was further confirmed by the HMBC experiment, which showed correlations of H-7 with C-1, C-2, C-6, C-9, C-4' and C-5', and correlations of H-8 with C-1, C-9, C-4', C-5' and C-6' (Fig. 1). In the NOESY spectrum, the H-8 exhibited cross peaks with $\mathrm{H}-2$ and $\mathrm{H}-6$, which indicated that the dihydrobenzofuran ring in 6 possessed a trans configuration. These spectral characteristics were also observed in the ${ }^{1} \mathrm{H},{ }^{13} \mathrm{C}$ and 2D-NMR spectra of compound 7 (Fig. 1), which indicated that 6 and 7 possessed the same planar structures. The full assignment of ${ }^{1} \mathrm{H}$ and ${ }^{13} \mathrm{C}$ NMR chemical shifts of $\mathbf{6}$ and 7 are shown in Table 2.

The absolute configuration in $\mathbf{6}$ was assigned by circular dichroism (CD) spectroscopy. The CD spectrum of 6 showed a negative Cotton effect at $254 \mathrm{~nm}$ and a positive one at $236 \mathrm{~nm}$. Based on comparison of the spectrum with those of the known dihydrobenzofuran-type compounds (Lemiere et al., 1995; Matsuda et al., 1996), the absolute stereochemistry at C-7 and $\mathrm{C}-8$ was assigned to be $7 S$ and $8 S$ configurations. In contrast, compound 7 exhibited a positive Cotton effect at $256 \mathrm{~nm}$ and a negative one at $224 \mathrm{~nm}$, and the configuration was assigned to be $7 R, 8 R$. Therefore, the structures of 6 and 7 were established as shown in Chart 
Compound 8 was obtained as an off-white amorphous powder. The molecular ion $\left([\mathrm{M}]^{+}\right)$ observed in the positive HR-FAB-MS at $\mathrm{m} / \mathrm{z} 868.2458$ (calcd. 868.2425) and the ${ }^{13} \mathrm{C}$ NMR spectral data (Table 2) showed the molecular formula to be $\mathrm{C}_{42} \mathrm{H}_{44} \mathrm{O}_{20}$. The ${ }^{1} \mathrm{H}$ and ${ }^{13} \mathrm{C}$ NMR spectral data of $\mathbf{8}$ were related to those of $\mathbf{1}$ and 10, except for the appearance of the signals in duplicate. In addition, the olefinic signals of caffeoyl moieties of $\mathbf{1}$ and $\mathbf{1 0}$ were replaced by four well-resolved double doublets $(J=10.0$ and $6.0 \mathrm{~Hz})$ at $\delta_{\mathrm{H}} 4.13(\mathrm{H}-7), 4.10\left(\mathrm{H}-7^{\prime}\right), 3.79$ (H-8') and $3.75(\mathrm{H}-8)$. Taking the molecular weight, which was exactly twice that of $\mathbf{1}$ or $\mathbf{1 0}$, into account, these NMR data indicated that $\mathbf{8}$ was a dimer of $\mathbf{1}$ or $\mathbf{1 0}$, and that $\mathbf{8}$ was a cyclobutane-type dimer formed by [2+2]-cycloaddition between two caffeoyl double bonds of 1 or 10.

The plane structure was established by the following 2D-NMR analysis. The COSY spectrum showed the connection between C-7-C-8, C-8-C-8', C-8'-C-7' and C-7'-C-7 (Fig. 2), which confirmed the presence of a cyclobutane ring in 8. From the HMQC spectrum, the signals at $\delta 46.0(\mathrm{C}-7), 45.9\left(\mathrm{C}-7^{\prime}\right), 45.3(\mathrm{C}-8)$ and $44.7\left(\mathrm{C}-8^{\prime}\right)$ were assigned to the cyclobutane methine carbons. In the HMBC spectrum, the former two methine carbons correlated with the catechol ring protons, and conversely, the H-7 and H-7' were correlated with the catechol ring carbons. The remaining two cyclobutane protons $\mathrm{H}-8$ and $\mathrm{H}-8^{\prime}$ were coupled with carboxyl carbons (C-9 and C-9'). The HMBC spectrum also showed correlations 
of the carboxyl carbons with the glucose C-6 methylene protons. These results further confirmed that $\mathbf{8}$ was a dimer of $\mathbf{1}$ or $\mathbf{1 0}$ formed by cyclobutane formation between two caffeoyl groups. Concerning the dimerization reaction, there are two possible arrangements of the two caffeoyl arbutin moieties, that is, head-to-head (truxinic type) or head-to-tail (truxillic type) (Hartley et al., 1990). This was determined by the appearance of the HMBC correlations of H-7 with C-1 and C-1'; H-7' with C-1' and C-1; and H-8 and H-8' with carboxyl carbons C-9 and C-9', which showed that compound 8 was a truxinic-type dimer (Fig. 2).

The relative configuration of the cyclobutane ring was established by the NOESY experiment. The NOESY spectrum not only showed clear NOE correlations between H-7(H-7') and H-2',6'(H-2,6), but also between H-7(H-7') and H-8(H-8') (Fig. 2), which are only possible for a trans configuration between H-7 and H-7', and cis configurations between H-7 and H-8 and between H-7' and H-8', which implied that the cyclobutane ring was in a $\mu$-truxinate arrangement. Furthermore, the ${ }^{1} \mathrm{H}-{ }^{1} \mathrm{H}$ coupling of cyclobutane protons (10.0 and $6.0 \mathrm{~Hz}$ ) was in agreement with that of a $\mu$-truxinate-type-related compounds ( $\mathrm{Lu}$ and Foo, 1999; Kamara et al., 2005). Therefore, compound 8 was deduced to be a $\mu$-truxinic-type dimer of $\mathbf{1}$, and its structure was established as shown in Chart 1.

Compound 9, named dunalianoside I, was obtained as an off-white amorphous powder. Its molecular formula was deduced to be $\mathrm{C}_{28} \mathrm{H}_{36} \mathrm{O}_{17}$ on the basis of the positive HR-FAB MS [m/z 644.1965 $\left([\mathrm{M}]^{+}\right)$, calcd. 644.1952], together with the ${ }^{13} \mathrm{C}$ NMR spectral data (see section 
3.9). The ${ }^{1} \mathrm{H}$ and ${ }^{13} \mathrm{C}$ NMR spectral data of $\mathbf{9}$ were very similar to those of compounds $\mathbf{1 1}$ and 15, which suggested that compound 9 was a conjugate of arbutin with monotropein. The downfield shifts of the glucose C-6 ( $\delta$ 64.6) and $\mathrm{H}_{2}-6[\delta 4.56(d d, J=12.0,1.8 \mathrm{~Hz})$ and 4.15 $(d d, J=12.0,6.8 \mathrm{~Hz})]$ signals of the arbutin moiety in $\mathbf{9}$ compared to those of $\mathbf{1 1}\left(\delta_{\mathrm{C}} 62.5, \delta_{\mathrm{H}}\right.$ 3.87 and 3.68), and the upfield shift of the carboxyl carbon at $\delta 168.5$ in 9 compared to $\delta$ 170.5 of 15, indicated acylation at the glucose C- 6 of the arbutin moiety by C-11 of the monotropein moiety. Therefore, the structure of $\mathbf{9}$ was established as shown in Chart 1.

Compounds 6-8 described here are the first examples of the caffeoyl arbutin dimers, and the arbutin-iridoid conjugate $\mathbf{9}$ was also first isolated from a natural source. It is apparent that the compounds 6 and 7 with a dihydrobenzofuran skeleton are generated by oxidative dimerization of compound 10. Many arylcoumaran neolignans formed by similar 8-5' linkage have also been found in various plants (Whiting, 1985). On the other hand, compound 8 is presumed to be formed by a photochemical [2+2] cyclo-addition of $\mathbf{1}$ (D'Auria and Vantaggi, 1992). Similar phenylpropanoid dimers with a cyclobutane ring are also known in higher plants (Hartley et al., 1990; Magiatis et al., 2002; Wang et al., 2003; Katerere et al., 2004). Dimers with the $\mu$-truxinate structures related to $\mathbf{8}$ have been isolated from Stachys aegyptiaca (El-Ansari et al., 1995), Salvia officinalis (Lu and Foo, 1999), and Monochaetum multiflorum (Isaza et al., 2001). 


\section{Concluding remarks}

To the best of our knowledge, the present study is the first chemical investigation of $V$. dunalianum, which led to the isolation of nine new compounds, together with 20 known ones. The most important feature of this Chinese local herbal tea is an abundance of caffeoyl esters of arbutin and related compounds; in particular, compound $\mathbf{1 0}$ was isolated at a $22 \%$ yield from the dried buds. So far, compound $\mathbf{1 0}$ has been isolated from the leaves of Hakea saligna (Proteaceae) (Manju et al., 1977), Viburnum sp. (Caprifoliaceae) (Iwagawa et al., 1988; Machida et al., 1991 and 1993), Grevillea robusta (Proteaceae) (Ahmed et al., 2000), Bacopa procumbens (Scrophulariaceae) (Pathak et al., 2005) and Veronica turrilliana (Plantaginaceae) (Kostadinova et al., 2007). However, the concentration in the buds of $V$. dunalianum seems to be highest, and the unusual accumulation of $\mathbf{1 0}$ was suggestive of its physiological role in this plant tissue.

In addition, it is well known that arbutin has been used as a diuretic and urinary anti-infective agent for centuries, either as a plant extract or in purified form (Robertson and Howard, 1987). The leaves of Arctostaphylos uva-ursi (Ericaceae) are used medicinally, as well as for preparing tea (Weiss and Fintelmann, 1997). Furthermore, arbutin is known to be an inhibitor of melanin biosynthesis (Akiu et al., 1988) and is used as a skin-whitening agent in cosmetics. Compound $\mathbf{1 0}$ and its analogues isolated in this study should be expected to possess similar properties, and detailed study of their bioactivities is now in progress. 


\section{Experimental}

\subsection{General experimental procedures}

IR spectra were obtained with a JASCO FT/IR-410 spectrophotometer, and UV spectra were measured by a JASCO V-560 UV/VIS spectrophotometer. Optical rotations were measured with a JASCO DIP-370 digital polarimeter whereas CD spectra measured with JASCO J-720w apparatus. ${ }^{1} \mathrm{H}$ and ${ }^{13} \mathrm{C}$ NMR spectra were recorded in $\mathrm{CD}_{3} \mathrm{OD}$ with Varian Unity plus 500 and Varian Gemini 300 spectrometers operating at 500 and $300 \mathrm{MHz}$ for ${ }^{1} \mathrm{H}$, and 125 and $75 \mathrm{MHz}$ for ${ }^{13} \mathrm{C}$, respectively. Coupling constants were expressed in $\mathrm{Hz}$, and chemical shifts were given on a $\delta(\mathrm{ppm})$ scale. MS was recorded on a JEOL JMS DX-303 spectrometer, and glycerol was used as a matrix for FAB-MS measurement. Column chromatography was preformed with Kieselgel 60 (70-230 mesh; Merck), Diaion HP20SS (Mitsubishi Chemical), MCI gel CHP 20P (75-150 $\mu \mathrm{m}$; Mitsubishi Chemical), Sephadex LH-20 (25-100 $\mu \mathrm{m}$; Pharmacia Fine Chemical), Chromatorex ODS (100-200 mesh; Fuji Silysia Chemical) and TSK gel Toyopearl HW-40F (Tosoh). TLC was performed on precoated Kieselgel $60 \mathrm{~F}_{254}$ plates $(0.2 \mathrm{~mm}$ thick; Merck), and spots were detected by UV illumination and by spraying with $2 \%$ ethanolic $\mathrm{FeCl}_{3}$ and $10 \%$ sulfuric acid reagent, followed by heating.

\subsection{Plant material}

The air-dried buds of $V$. dunalianum Wight (Ericaceae) were collected from Wuding, Yunnan, People's Republic of China, and identified by Prof. Chong-Ren Yang. The voucher specimen (KUN No. 0800238) was deposit in Herbarium of Kunming Institute of Botany, Chinese Academy of Sciences.

\subsection{Extraction and isolation}


The air-dried buds $(1.77 \mathrm{~kg})$ of $V$. dunalianum were extracted with $60 \%$ aqueous acetone at room temperature by maceration. After filtration, the extract was concentrated under reduced pressure at $40^{\circ} \mathrm{C}$ until acetone was removed, and then the aqueous solution was defatted by partition with ether. The aqueous layer was further concentrated to remove residual organic solvent and left to stand at room temperature overnight to yield large amounts of off-white crystalline powder of compound $\mathbf{1 0}$ (316 g). TLC analysis showed that the crystalline powder was an almost pure compound. The filtrate remaining after the first crop of $\mathbf{1 0}$ was further concentrated to give another crop of $\mathbf{1 0}$ (155 g). The crystalline powder was combined and recrystallized from water to yield compound $\mathbf{1 0}$ as colorless needles (390 g).

The filtrate was concentrated, and the residue (472 g) was separated to three fractions (Frs. 1-3) by Diaion HP-20 column chromatography $(\mathrm{CC})(10 \mathrm{~cm}$ i.d. $\times 35 \mathrm{~cm})$, eluted with a gradient solvent system of water/methanol (1:0-0:1). Fr. 1 (366 g) was subjected to Diaion HP20SS column eluted with water/methanol $(1: 0-0: 1)$ to give three fractions, and then Fr. 1-1 (256 g) was further fractionated into four (Frs. 1-1-1 to 1-1-4) by CC on Diaion HP20SS eluted with water/methanol (1:0-0:1) containing $0.1 \%$ TFA. Fr. 2 (91 g) was fractionated by Sephadex LH-20 CC eluted with water/methanol (1:0-0:1) to give four fractions (Frs. 2-1 to 2-4). Fr. 1-1-1 was subjected to Chromatorex ODS CC (water/methanol, 1:0-1:1), followed with silica gel CC (chloroform/methanol/water , 90:10:1-70:30:5) to yield 11 (9.3 g), 15 (1.48 g), 16 (15 mg) and 28 (947 mg). Fraction 1-1-2 was passed through Sephadex LH-20 $\left(\mathrm{H}_{2} \mathrm{O}-\mathrm{MeOH}, 1: 0-0: 1\right)$, Chromatorex ODS (water/methanol, 1:0-0:1), and a silica gel column (chloroform/methanol/water, 90:10:1-70:30:5) to yield 19 (448 mg) and 20 (227 mg). Repeated CC of Fr. 1-1-3 with Sephadex LH-20 (water/methanol, 1:0-0:1), Chromatorex ODS (water/methanol, 1:0-0:1), Toyopearl HW-40F (60\% methanol), and silica gel (chloroform/methanol/water, 90:10:1-70:30:5) to give $8(25.7 \mathrm{mg}), \mathbf{9}(76.6 \mathrm{mg}), \mathbf{1 0}(31 \mathrm{mg})$ and $22(7.3 \mathrm{mg})$. Fr. 1-1-4 
was repeatedly chromatographed over Sephadex LH-20, MCI-gel CHP20P with water/methanol (1:0-0:1) respectively, and silica gel CC (chloroform/methanol/water, 90:10:1-70:30:5) to give $12(614 \mathrm{mg}), \mathbf{1 7}(33.4 \mathrm{mg}) \mathbf{1 8}(51.7 \mathrm{mg})$ and $25(22.4 \mathrm{~g})$.

Fr. 2-1 (20 g) was repeatedly separated by $\mathrm{CC}$ with silica gel CC (chloroform/methanol/water, 90:10:1-70:30:5), Chromatorex ODS and MCI-gel CHP20P with water/methanol (1:0-0:1) respectively, to yield 4 (6.7 mg), $14(6.7 \mathrm{mg}), 21(33.8 \mathrm{mg}), \mathbf{2 6}$ (2.0 g), $27(33.3 \mathrm{mg})$ and $29(30 \mathrm{mg})$. Similar separation for Fr. 2-2 (15 g) was performed to give 1 (278 mg), 2 (43 mg), 3 (43.7 mg), $13(5.8 \mathrm{mg})$ and 24 (92 mg). Fr. 2-3 (10 g) was subjected to silica gel CC (chloroform/methanol/water, 90:10:1-70:30:5), followed by Chromatorex ODS (water/methanol, 1:0-0:1) to yield $5(3.2 \mathrm{~g})$ and a mixture of 6 and 7. This mixture was further separated by CC with Sephadex LH-20 (ethanol) and Toyopearl HW-40F (60\% methanol) to yield $6(83.2 \mathrm{mg})$ and $7(46.4 \mathrm{mg})$. Fr. 2-4 (5 g) was subjected to silica gel CC (chloroform/methanol/water, 90:10:1-70:30:5) and MCI-gel CHP20P (water/methanol, 1:0-0:1) to yield $23(54.3 \mathrm{mg})$.

\subsection{Dunalianoside A (1)}

An off-white amorphous powder, $[\alpha]_{\mathrm{D}}{ }^{26}=-64.6(c 0.1, \mathrm{MeOH}) ; \mathrm{IR} v_{\max } \mathrm{cm}^{-1}: 3357,1686$, $1607,1509,1444,1357,1271,1202,1070,827,776$; UV $\lambda_{\max }(\mathrm{MeOH}) \mathrm{nm}(\log \varepsilon): 327$ (4.14), 295 (4.09), 247sh (3.96), 220 (4.30). FAB-MS (positive ion mode): m/z 527 [M+Gly] $]^{+}, 457$ $[\mathrm{M}+\mathrm{Na}]^{+}, 435[\mathrm{M}+\mathrm{H}]^{+}$; HR-FAB MS (positive ion mode): $\mathrm{m} / \mathrm{z} 434.1234\left([\mathrm{M}]^{+}\right.$) for $\mathrm{C}_{21} \mathrm{H}_{22} \mathrm{O}_{10}$ (calcd. for 434.1213). For ${ }^{1} \mathrm{H}$ and ${ }^{13} \mathrm{C}$ NMR spectral data, see Table 1.

\subsection{Dunalianoside B (2)}

An off-white amorphous powder, $[\alpha]_{\mathrm{D}}{ }^{26}=-67.0(c 0.1, \mathrm{MeOH}) ; \mathrm{IR} v_{\max } \mathrm{cm}^{-1}: 3372,1686$, $1607,1510,1446,1367,1284,1200,1075,1034,850,805 ; \mathrm{UV} \lambda_{\max }(\mathrm{MeOH}) \mathrm{nm}(\log \varepsilon): 328$ 
(4.20), 290 (4.11), 245sh (4.00), 220 (4.32). FAB-MS (positive ion mode): m/z $473[\mathrm{M}+\mathrm{Na}]^{+}$, $451[\mathrm{M}+\mathrm{H}]^{+}$; HR-FAB MS (positive ion mode): $\mathrm{m} / \mathrm{z} 451.1213\left([\mathrm{M}+\mathrm{H}]^{+}\right.$) for $\mathrm{C}_{21} \mathrm{H}_{23} \mathrm{O}_{11}$ (calcd. for 451.1240$)$. For ${ }^{1} \mathrm{H}$ and ${ }^{13} \mathrm{C}$ NMR spectral data, see Table 1.

\subsection{Dunalianoside C (3)}

An off-white amorphous powder, $[\alpha]_{\mathrm{D}}^{23}=-23.6(c 0.1, \mathrm{MeOH}) ; \mathrm{IR} v_{\max } \mathrm{cm}^{-1}: 3386,1690$, $1608,1513,1446,1353,1281,1185,1071,854,810$; UV $\lambda_{\max }(\mathrm{MeOH}) \mathrm{nm}(\log \varepsilon): 327$ (4.14), 294 (4.11), 248sh (3.99). FAB-MS (positive ion mode): $\mathrm{m} / \mathrm{z} 473[\mathrm{M}+\mathrm{Na}]^{+}, 451[\mathrm{M}+\mathrm{H}]^{+}$; HR-FAB MS (positive ion mode): $m / z 451.1224\left([\mathrm{M}+\mathrm{H}]^{+}\right.$) for $\mathrm{C}_{21} \mathrm{H}_{23} \mathrm{O}_{11}$ (calcd. for 451.1240). For ${ }^{1} \mathrm{H}$ and ${ }^{13} \mathrm{C}$ NMR spectral data, see Table 1.

\subsection{Dunalianoside $D(4)$}

An off-white amorphous powder, $[\alpha]_{\mathrm{D}}^{23}=-41.2(c 0.1, \mathrm{MeOH}) ; \mathrm{IR} v_{\max } \mathrm{cm}^{-1}: 3362,1693$, $1604,1511,1451,1370,1261,1197,1070,947,801$; UV $\lambda_{\max }(\mathrm{MeOH}) \mathrm{nm}(\log \varepsilon): 329$ (4.09), 289 (4.05), 248sh (3.90). FAB-MS (positive ion mode): $m / z 557[\mathrm{M}+\mathrm{Gly}]^{+}, 487[\mathrm{M}+\mathrm{Na}]^{+}, 465$ $[\mathrm{M}+\mathrm{H}]^{+}$; HR-FAB MS (positive ion mode): $\mathrm{m} / \mathrm{z} 464.1320\left([\mathrm{M}]^{+}\right.$) for $\mathrm{C}_{22} \mathrm{H}_{24} \mathrm{O}_{11}$ (calcd. for 464.1318). For ${ }^{1} \mathrm{H}$ and ${ }^{13} \mathrm{C}$ NMR spectral data, see Table 1.

\subsection{Dunalianoside E (5)}

An off-white amorphous powder, $[\alpha]_{\mathrm{D}}{ }^{26}=-67.3(c 0.1, \mathrm{MeOH}) ; \mathrm{IR} v_{\max } \mathrm{cm}^{-1}: 3380,1686$, $1600,1508,1443,1374,1209,1076,1034,829,775 ; \mathrm{UV} \lambda_{\max }(\mathrm{MeOH}) \mathrm{nm}(\log \varepsilon): 327$ (4.22), 295 (4.14), 245sh (4.01), 220 (4.32). FAB-MS (positive ion mode): m/z $569[\mathrm{M}+\mathrm{Gly}]^{+}, 499$ $[\mathrm{M}+\mathrm{Na}]^{+}, 477[\mathrm{M}+\mathrm{H}]^{+}, 367\left[\mathrm{M}-\mathrm{C}_{6} \mathrm{H}_{5} \mathrm{O}_{2}\right]^{+}$; HR-FAB MS (positive ion mode): $\mathrm{m} / \mathrm{z} 476.1303$ $\left([\mathrm{M}]^{+}\right.$) for $\mathrm{C}_{23} \mathrm{H}_{24} \mathrm{O}_{11}$ (calcd. for 476.1308). For ${ }^{1} \mathrm{H}$ and ${ }^{13} \mathrm{C}$ NMR spectral data, see Table 1 . 


\subsection{Dunalianoside F (6)}

An off-white amorphous powder, $[\alpha]_{\mathrm{D}}{ }^{26}=-32.6(c$ 0.1, $\mathrm{MeOH}), \mathrm{CD}(\mathrm{MeOH}) \mathrm{nm}(\Delta \varepsilon): 236$ (+4.13), $254(-3.23), 275(+1.15) ;$ IR $v_{\max } \mathrm{cm}^{-1}: 3424,1722,1690,1610,1512,1450,1344$ 1285, 1220, 1139, 1077, 832, 777; UV $\lambda_{\max }(\mathrm{MeOH}) \mathrm{nm}(\log \varepsilon): 330$ (4.31), 289 (4.26), 223 (4.59). FAB-MS (positive ion mode): $\mathrm{m} / \mathrm{z} 959[\mathrm{M}+\mathrm{Gly}]^{+}, 889[\mathrm{M}+\mathrm{Na}]^{+}, 867[\mathrm{M}+\mathrm{H}]^{+}$; HR-FAB MS (positive ion mode): $m / z$ 866.2231 ([M] $]^{+}$) for $\mathrm{C}_{42} \mathrm{H}_{42} \mathrm{O}_{20}$ (calcd. for 866.2269). For ${ }^{1} \mathrm{H}$ and ${ }^{13} \mathrm{C}$ NMR spectral data, see Table 2.

\subsection{Dunalianoside G (7)}

An off-white amorphous powder, $[\alpha]_{\mathrm{D}}^{26}=-36.1(c 0.1, \mathrm{MeOH}), \mathrm{CD}(\mathrm{MeOH}) \mathrm{nm}(\Delta \varepsilon): 224$ (-14.04), $256(+1.74), 283(-1.22) ;$ IR $v_{\max } \mathrm{cm}^{-1}: 3403,1719,1688,1608,1508,1447,1342$, 1279, 1210, 1140, 1071, 831, 777; UV $\lambda_{\max }(\mathrm{MeOH}) \mathrm{nm}(\log \varepsilon): 328$ (4.32), 290 (4.26), 223 (4.60). FAB-MS (positive ion mode): $\mathrm{m} / \mathrm{z} 959[\mathrm{M}+\mathrm{Gly}]^{+}, 889[\mathrm{M}+\mathrm{Na}]^{+}, 867[\mathrm{M}+\mathrm{H}]^{+}$; HR-FAB MS (positive ion mode): $\mathrm{m} / \mathrm{z} 867.2394\left([\mathrm{M}+\mathrm{H}]^{+}\right.$) for $\mathrm{C}_{42} \mathrm{H}_{43} \mathrm{O}_{20}$ (calcd. for 867.2347). For ${ }^{1} \mathrm{H}$ and ${ }^{13} \mathrm{C}$ NMR spectral data, see Table 2.

\subsection{Dunalianoside H (8)}

An off-white amorphous powder, $[\alpha]_{\mathrm{D}}{ }^{26}=-37.2(c 0.1, \mathrm{MeOH}) ; \mathrm{IR} v_{\max } \mathrm{cm}^{-1}: 3461,1729$, $1606,1515,1449,1370,1289,1089,831,778$; UV $\lambda_{\max }(\mathrm{MeOH}) \mathrm{nm}(\log \varepsilon): 325 \mathrm{sh}(3.62)$, 285 (4.07). FAB-MS (positive ion mode): $\mathrm{m} / \mathrm{z} 891[\mathrm{M}+\mathrm{Na}]^{+}, 868[\mathrm{M}]^{+}$; HR-FAB MS (positive ion mode): $\mathrm{m} / \mathrm{z} 868.2458\left([\mathrm{M}]^{+}\right)$for $\mathrm{C}_{42} \mathrm{H}_{44} \mathrm{O}_{20}$ (calcd. for 868.2425). For ${ }^{1} \mathrm{H}$ and ${ }^{13} \mathrm{C} \mathrm{NMR}$ spectral data, see Table 2 .

\subsection{Dunalianoside I (9)}

An off-white amorphous powder, $[\alpha]_{\mathrm{D}}^{26}=-117.0(c 0.1, \mathrm{MeOH}) ; \mathrm{IR} v_{\max } \mathrm{cm}^{-1}: 3427,1695$, 
$1639,1511,1454,1373,1288,1216,1107,948,924,874,777$; UV $\lambda_{\max }(\mathrm{MeOH}) \mathrm{nm}(\log \varepsilon)$ : 285 (3.41), 225 (4.14). FAB-MS (positive ion mode): m/z $737[\mathrm{M}+\mathrm{Gly}+\mathrm{H}]^{+}, 667[\mathrm{M}+\mathrm{Na}]^{+}$, $645[\mathrm{M}+\mathrm{H}]^{+}, 644[\mathrm{M}]^{+}$; HR-FAB MS (positive ion mode): $\mathrm{m} / \mathrm{z} 644.1965$ ([M] $]^{+}$) for $\mathrm{C}_{28} \mathrm{H}_{36} \mathrm{O}_{17}$ (calcd. for 644.1952). ${ }^{1} \mathrm{H} \mathrm{NMR}\left(\mathrm{CD}_{3} \mathrm{OD}, 300 \mathrm{MHz}\right)$ : arbutin moiety, $\delta 6.92(2 \mathrm{H}, d, J=9.0 \mathrm{~Hz}$, H-2,6), $6.68(2 \mathrm{H}, d, J=9.0 \mathrm{~Hz}, \mathrm{H}-3,5), 4.74\left(d, J=7.6 \mathrm{~Hz}, \mathrm{H}-1^{\prime}\right), 4.56(d d, J=12.0,1.8 \mathrm{~Hz}$, H-6'), $4.15\left(d d, J=12.0,6.8 \mathrm{~Hz}, \mathrm{H}-6^{\prime}\right), 3.40\left(t, J=8.8 \mathrm{~Hz}, \mathrm{H}-5^{\prime}\right), 3.30 \sim 3.38\left(m, \mathrm{H}-2^{\prime}, 3^{\prime}, 4^{\prime}\right)$; monotropein moiety, $\delta 7.44(d, J=1.2 \mathrm{~Hz}, \mathrm{H}-3 "), 6.21$ (dd, $J=5.8,2.6 \mathrm{~Hz}, \mathrm{H}-6 "), 5.62$ (dd, $J$ $=5.8,2.2 \mathrm{~Hz}, \mathrm{H}-7 "), 5.60$ (d, $J=2.6 \mathrm{~Hz}, \mathrm{H}-1 "), 4.68$ (d, $\left.J=8.0 \mathrm{~Hz}, \mathrm{H}-1{ }^{\prime \prime \prime}\right), 3.88$ (dd, $J=12.0$, $\left.1.5 \mathrm{~Hz}, \mathrm{H}-6^{\prime \prime}\right), 3.67$ (dd, $\left.J=12.0,5.2 \mathrm{~Hz}, \mathrm{H}-6^{\prime \prime \prime}\right), 3.61$ (d, $\left.J=2.2 \mathrm{~Hz}, \mathrm{H}-10 "\right), 3.58$ (dd, $J=8.6$, $2.6 \mathrm{~Hz}, \mathrm{H}-5 "), 3.40$ ( $\left.t, J=8.8 \mathrm{~Hz}, \mathrm{H}-5^{\prime \prime \prime}\right), 3.30 \sim 3.38$ (m, H-3"',4"'), 3.21 (dd, $J=8.8,8.0 \mathrm{~Hz}$, H-2"'), 2.72 (dd, $J=8.6,2.6 \mathrm{~Hz}, \mathrm{H}-9 ") .{ }^{13} \mathrm{C}$ NMR ( $\left.\mathrm{CD}_{3} \mathrm{OD}, 75 \mathrm{MHz}\right)$ : arbutin moiety, $\delta 153.9$ (C-1), 152.2 (C-4), 119.4 (C-2,6), 116.7 (C-3,5), 103.4 (C-1'), 77.9 (C-3'), 75.4 (C-5'), 74.9 (C-2'), 71.4 (C-4'), 64.6 (C-6'); monotropein moiety, $\delta 168.5$ (C-11"), 152.9 (C-3"), 137.9 (C-6"), 133.9 (C-7"), 110.9 (C-4"), 100.1 (C-1"'), 95.4 (C-1"), 86.1 (C-8"), 78.3 (C-5"'), 77.9 (C-3"'), 74.7 (C-2"'), 71.9 (C-4"'), 68.4 (C-10"), 62.6 (C-6"'), 45.7 (C-9"), 39.1 (C-5").

\section{Acknowledgement}

The authors are grateful to Mr. K. Inada and Mr. N. Yamaguchi (Nagasaki University) for NMR and MS measurements. 


\section{Figures and Legends:}

Chart 1. Caffeoyl derivatives of arbutin isolated from Vaccinium dunalianum

\section{References}

Ahmed, A.S., Nakamura, N., Meselhy, M.R., Makhboul, M.A., El-Emary, N., Hattori, M., 2000. Phenolic constituents from Grevillea robusta. Phytochemistry 53, 149-154.

Akiu, S., Suzuki, Y., Fujinuma, Y., Asahara, T., Fukada, M., 1988. Inhibitory Effect of Arbutin on Melanogenesis: Biochemical Study in Cultured B16 Cells and Effect on the UV-induced Pigmentation in Human Skin. Proc. Jpn. Soc. Invest. Dermatol. 12, 138-139.

D’Auria, M. and Vantaggi, A., 1992. Phytochemical dimerization of methoxy substituted cinnamic acid methyl esters. Tetrahedron 48, 2523-2528.

Dommisse, R.A., van Hoof, L., Vlietinck, A.J., 1986. Structural analysis of phenolic glucosides from Salicaceae by NMR spectroscopy. Phytochemistry 25, 1201-1204.

El-Ansari, M.A., Nawwar, M.A., Saleh, N.A.M., 1995. Stachysetin, a diapigenin-7-glucoside-p,p'-dihydroxy-truxinate from Stachys aegyptiaca. Phytochemistry 40, 1543-1548.

Hartley, R.D., Morrison III, W.H., Balza, F., Towers, G.H.N., 1990. Substituted truxillic and 
truxinic acids in cell walls of Cynodon dactylon. Phytochemistry 29, 3699-3704.

Isaza, J.A., Ito, H., Yoshida, T., 2001. A Flavonol glycoside-lignan ester and accompanying acylated glucosides from Monochaetum multiflorum. Phytochemistry 58, 321-327.

Jensen, H.D., Krogfelt, K.A., Cornett, C., Hansen, S.H., Christensen, S.B., 2002. Hydrophilic carboxylic acids and iridoid glycosides in the juice of American and European cranberries (Vaccinium macrocarpon and V. oxycoccos), lingonberries (V. vitis-idaea), and blueberries (V. myrtillus). J. Agric. Food Chem. 50, 6871-6874.

Kamara, B.I., Manong, D.T.L., Brandt, E.V., 2005. Isolation and Synthesis of dimeric dihydrochalcone from Agapanthus africanus. Phytochemistry 66, 1126-1132.

Katerere, D.R., Gray, A.I., Kennedy, A.R., Nash, R.J., Waigh, R.D., 2004. Cyclobutanes from Combretum albopunctatum. Phytochemistry 65, 433-438.

Kitajima, J., Ishikawa, T., Tanaka, Y., Ono, M., Ito, Y., Nohara, T., 1998. Water-soluble constituents of fennel. V. ${ }^{1)}$ Glycosides of aromatic compounds. Chem. Pharm. Bull. 46, 1587-1590.

Kostadinova, E.P., Alipieva, K.I., Kokubun, T., Taskova, R.M., Handjieva, N.V., 2007. Phenylethanoids, iridoids and spirostanol saponin from Veronica turrilliana. Phytochemistry 68, 1321-1326.

Lemière, G., Gao, M., Groot, A.D., Dommisse, R., Lepoivre, J., Pieters, L., Buss, V., 1995. 3',4-Di-O-methylcedrusin: synthesis, resolution and absolute configuration. J. Chem. 
Soc., Perkin Trans. I, 1775-1779.

Lu, Y.R. and Foo, L.Y., 1999. Rosmarinic acid derivatives from Salvia officinalis. Phytochemistry 51, 91-94.

Machida, K., Nakano, Y., Kikuchi, M., 1991. Phenolic glycosides from Viburnum dilatatum. Phytochemistry 30, 2013-2014.

Machida, K. and Kikuchi, M., 1993. Studies on the constituents of Viburnum species. On phenolic glycosides from the leaves of Viburnum wrightii Miq. Chem. Pharm. Bull. 41, $248-251$.

Magiatis, P., Skaltsounis, A.-L., Tillequin, F., Seguin, E., Cosson, J.-P., 2002. Coelobillardin, an iridoid glucoside dimer from Coelospermum billardieri. Phytochemistry 60, 415-418.

Manju, M., Varma, R.S., Parthasarathy, M.R., 1977. New Arbutin Derivatives from Leaves of Gervillea robusta and Hakea saligna. Phytochemistry 16, 793-794.

Matsuda, N., Sato, H., Yaoita, Y., Kikuchi, M., 1996. Isolation and absolute structures of the neolignan glycosides with the enantiometric aglycones from the leaves of Viburnum awabuki K. Koch ${ }^{1)}$. Chem. Pharm. Bull. 44, 1122-1123.

Morishita, H., Iwahashi, H., Osaka, N., Kido, R., 1984. Chromatographic separation and identification of naturally occrrring chlorogenic Acids by ${ }^{1} \mathrm{H}$ nuclear magnetic resonance spectroscopy and mass spectrometry. J. Chromatogr., A 315, 253-260.

Moyer, R.A., Hummer, K.E., Finn, C.E., Frei, B., Wrolstad, R.E., 2002. Anthocyanins, 
phenolics and antioxidant capacity in diverse small fruits: Vaccinium, Rubus, and Ribes. J. Agric. Food Chem. 50, 519-525.

Numata, A., Takahashi, C., Fujiki, R., Kitano, E., Kitajima, A., Takemura, T., 1990. Plant constituents biologically active to insects. VI. ${ }^{1)}$ Antifeedants for larvae of the yellow butterfly, Eurema hecabe mandarina, in Osmunda japonica. (2). Chem. Pharm. Bull. 38, $2862-2865$.

Ono, M., Ito, Y., Ishikawa, T., Kitajima, J., Tanaka, Y., Niiho, Y., Nohara, T., 1996. Five new monoterpene glycosides and other compounds from Foeniculi Fructus (fruit of Foeniculum vulgare Miller). Chem. Pharm. Bull. 44, 337-342.

Pathak, A., Kulshreshtha, D.K., Maurya, R., 2005. Chemical Constituents of Bacopa procumbens. Nat. Prod. Res. 19, 131-136.

Prior, R.L., Cao, G.H., Martin, A., Sofic, E., McEwen, J., O’Brien, C., Lischner, N., Ehlenfeldt, M., Kalt, W., Krewer, G., Mainland, C.M., 1998. Antioxidant capacity as influenced by total phenolic and anthocyanin content, maturity, and variety of Vaccinium species. J. Agric. Food Chem. 46, 2686-2693.

Robertson, J.A. and Howard, L.A., 1987. Effects of Carbohydrates on Growth of Ureoplasma urealyticum and Mycoplasma hominis. J. Clin. Microbiol. 25, 160-161.

Shimomura, H., Sashida, Y., Adachi, T., 1987. Phenolic glucosides from Prunus grayana. Phytochemistry 26, 249-251. 
Shoyama, Y., Hatano, K., Nishioka, I., Yamagishi, T., 1987. Phenolic glycosides from Lilium longiflorum. Phytochemistry 26, 2965-2968.

Taruscio, T.G., Barney, D.L., Exon, J., 2004. Content and profile of flavonoid and phenolic acids compounds in conjunction with the antioxidant capacity for a variety of northwest Vaccinium Berries. J. Agric. Food Chem. 51, 3169-3176.

Vvedenskaya, I.O., Rosen, R.T., Guido, J.E., Russell, D.J., Mills, K.A., Vorsa, N., 2004. Characterization of flavonols in cranberry (Vaccinium macrocarpon) powder. J. Agric. Food Chem. 52, 188-195.

Wada, H., Kido, T., Tanaka, N., Murakami, T., Saiki, Y., Chen, C.M., 1992. Chemical and chemotaxonomical studies of Ferns. LXXXI. ${ }^{1)}$ Characteristic lignans of blechnaceous ferns. Chem. Pharm. Bull. 40, 2099-2101.

Wang, N., Yao, X., Ishii, R., Kitanaka, S., 2003. Bioactive surcose esters from Bidens parviflora. Phytochemistry 62, 741-746.

Weiss, R.F. and Fintelmann, V., 1997. Lehrbuch der Phytotherapie. Stuttgart: Hippokrates Verlag. p. 47.

Whiting, D.A., 1985. Lignans and neolignans. Nat. Prod. Rep. 2, 191-212. 


\section{Figure Legends:}

Fig. 1 Selected NOE correlations for 2-4, and ${ }^{1} \mathrm{H}-{ }^{1} \mathrm{H}$ COSY and HMBC correlations for 5-7.

Fig. 2 Selected ${ }^{1} \mathrm{H}^{-1} \mathrm{H}$ COSY, HMBC and NOE correlations for 8. 


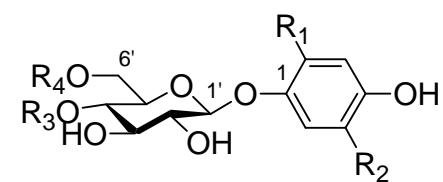

$1 \mathrm{R}_{1}=\mathrm{R}_{2}=\mathrm{R}_{3}=\mathrm{H}, \mathrm{R}_{4}=$ cis-caffeoyl

$2 R_{1}=O H, R_{2}=R_{3}=H, R_{4}=$ trans-caffeoyl

$3 \mathrm{R}_{1}=\mathrm{R}_{3}=\mathrm{H}, \mathrm{R}_{2}=\mathrm{OH}, \mathrm{R}_{4}=$ trans-caffeoyl

$4 \mathrm{R}_{1}=\mathrm{R}_{3}=\mathrm{H}, \mathrm{R}_{2}=\mathrm{OCH}_{3}, \mathrm{R}_{4}=$ trans-caffeoyl

$5 \quad R_{1}=R_{2}=H, R_{3}=A c, R_{4}=$ trans-caffeoyl

$10 \mathrm{R}_{1}=\mathrm{R}_{2}=\mathrm{R}_{3}=\mathrm{H}, \mathrm{R}_{4}=$ trans-caffeoyl

$11 \mathrm{R}_{1}=\mathrm{R}_{2}=\mathrm{R}_{3}=\mathrm{R}_{4}=\mathrm{H}$
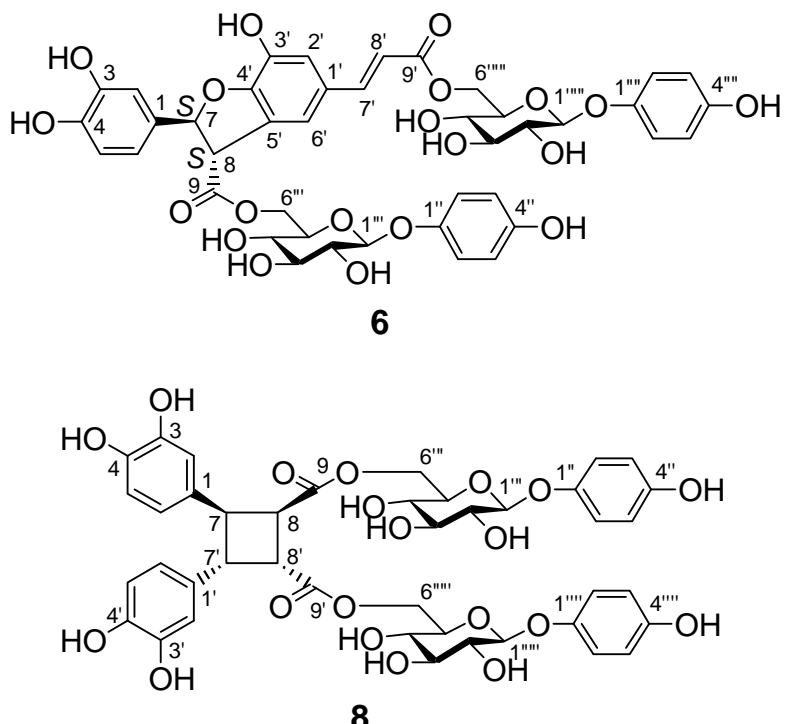
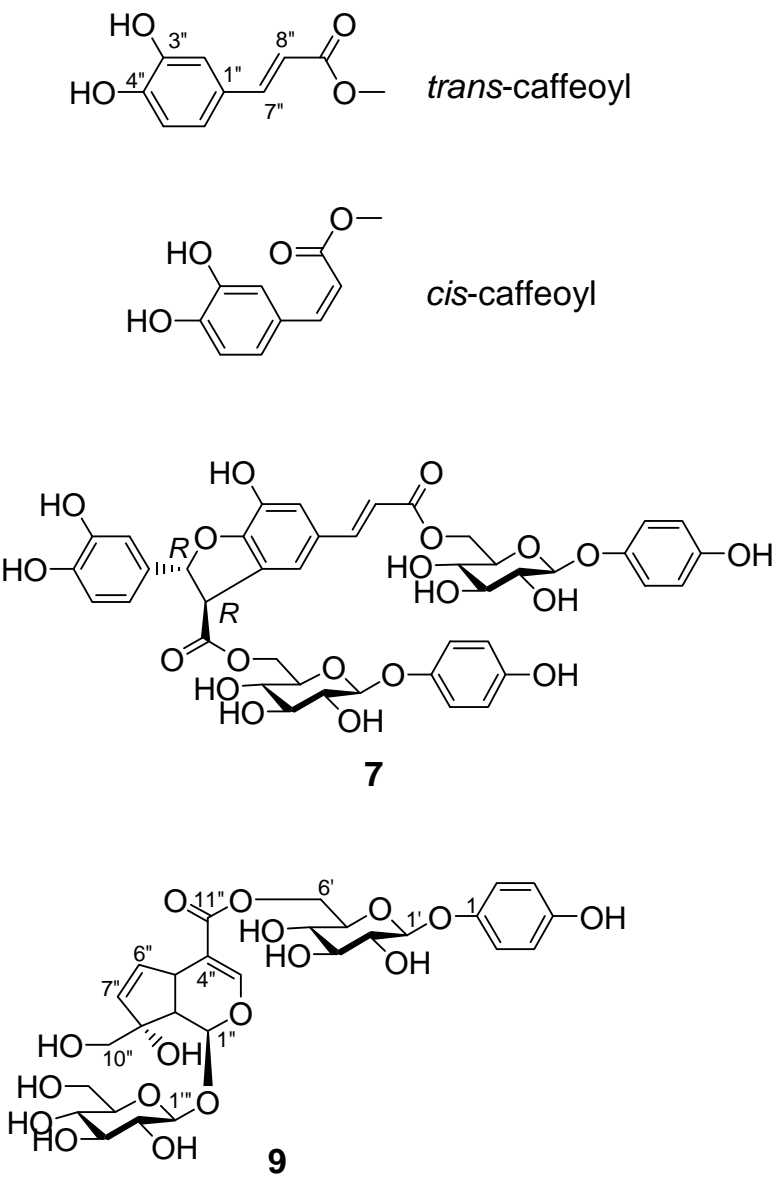

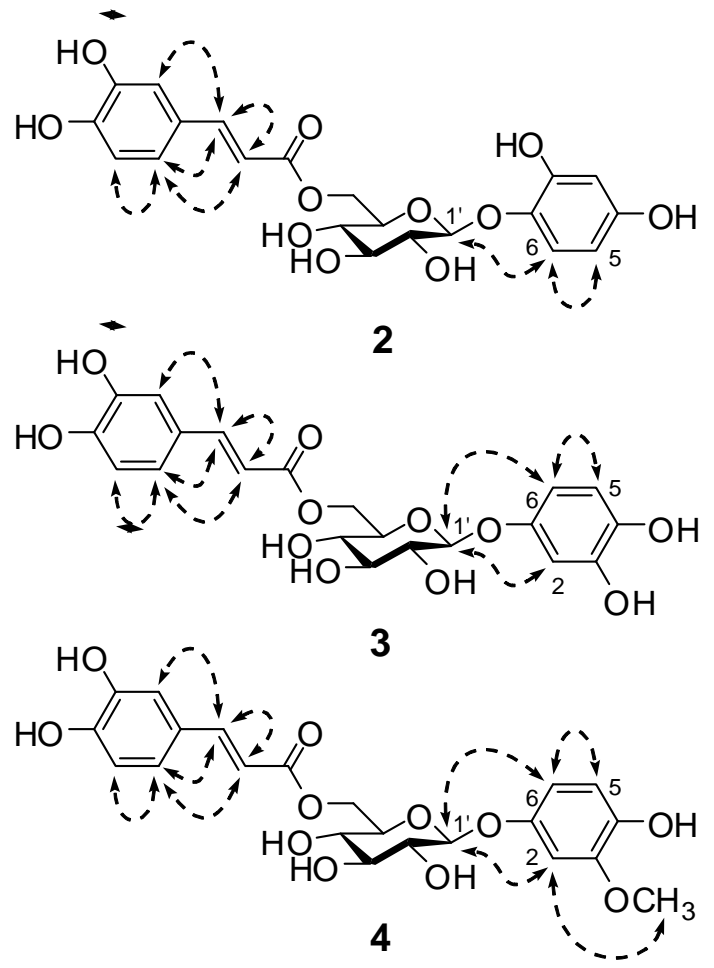

$\because$ NOE $-{ }^{1}{ }_{-1}{ }^{1} \mathrm{H} \operatorname{COSY} \curvearrowleft$ HMBC

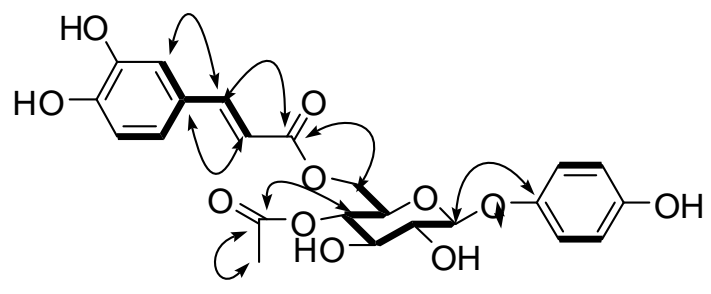

5

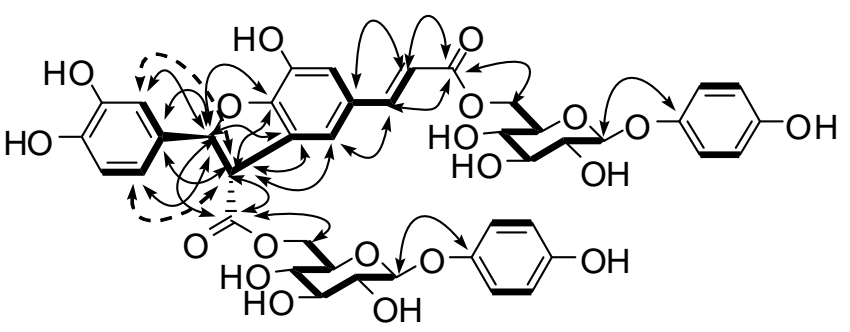

6

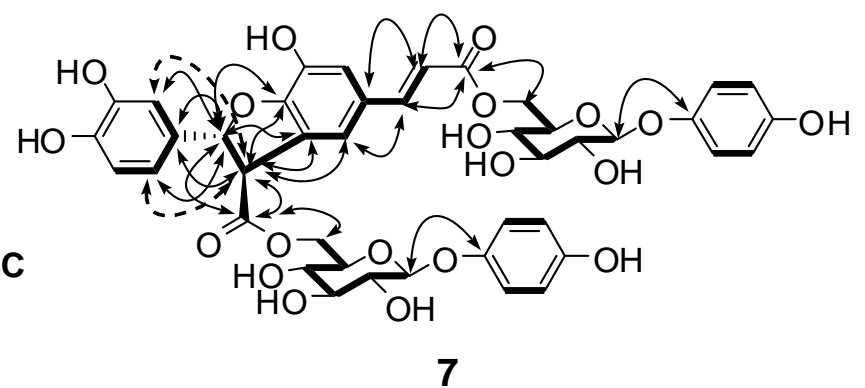

Fig. 1 

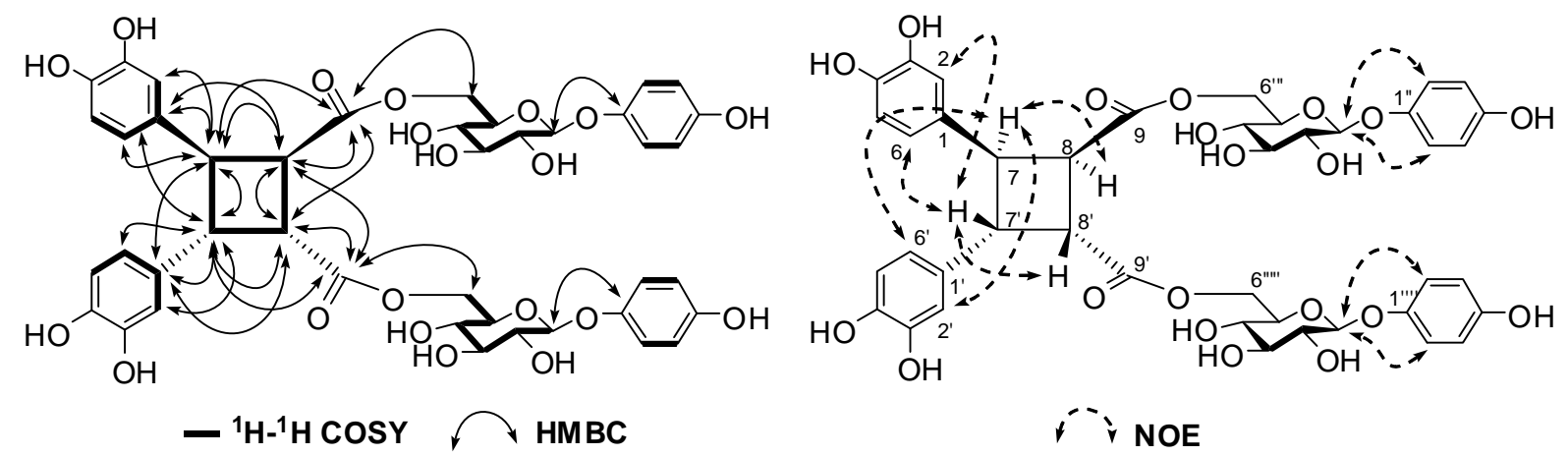

Fig. 2 
Table $1{ }^{1} \mathrm{H}(500 \mathrm{MHz})$ and ${ }^{13} \mathrm{C}(125 \mathrm{MHz})$ NMR spectral data for compounds $\mathbf{1}-\mathbf{5}$ measured in $\mathrm{CD}_{3} \mathrm{OD}$

\begin{tabular}{|c|c|c|c|c|c|c|c|c|c|c|}
\hline \multirow[b]{2}{*}{ Position } & \multicolumn{2}{|r|}{1} & \multicolumn{2}{|r|}{2} & \multicolumn{2}{|r|}{3} & \multicolumn{2}{|r|}{4} & \multicolumn{2}{|c|}{5} \\
\hline & $\delta_{\mathrm{C}}$ & $\delta_{\mathrm{H}}(\mathrm{J}$ in $\mathrm{Hz})$ & $\delta_{\mathrm{C}}$ & $\delta_{\mathrm{H}}(\mathrm{J}$ in $\mathrm{Hz})$ & $\delta_{\mathrm{C}}$ & $\delta_{\mathrm{H}}(\mathrm{J}$ in $\mathrm{Hz})$ & $\delta_{\mathrm{C}}$ & $\delta_{\mathrm{H}}(\mathrm{J}$ in $\mathrm{Hz})$ & $\delta_{\mathrm{C}}$ & $\delta_{\mathrm{H}}(J$ in $\mathrm{Hz})$ \\
\hline 1 & 152.1 & & 140.0 & & 152.4 & & 152.6 & & 152.1 & \\
\hline 2 & 119.5 & $6.91 d(8.7)$ & 147.2 & & 106.5 & $6.64 d(1.8)$ & 104.1 & $6.70 d(1.8)$ & 119.6 & $6.95 d(9.0)$ \\
\hline 3 & 116.8 & $6.65 d(8.7)$ & 105.8 & $6.27 d(2.7)$ & 146.5 & & 149.2 & & 116.7 & $6.67 d(9.0)$ \\
\hline 4 & 153.7 & & 155.3 & & 141.5 & & 142.5 & & 153.9 & \\
\hline 5 & 116.8 & $6.65 d(8.7)$ & 107.1 & $6.09 d d(8.7,2.7)$ & 116.0 & $6.63 d(8.4)$ & 116.0 & $6.60 d(8.8)$ & 116.7 & $6.67 d(9.0)$ \\
\hline 6 & 119.5 & $6.91 d(8.7)$ & 121.0 & $6.93 d(8.7)$ & 108.8 & $6.46 d d(8.4,1.8)$ & 110.3 & $6.53 d d(8.8,1.8)$ & 119.6 & $6.95 d(9.0)$ \\
\hline $3-\mathrm{OCH}_{3}$ & & & & & & & 56.4 & $3.74 \mathrm{~s}$ & & \\
\hline $1^{\prime}$ & 103.5 & $4.70 d(7.2)$ & 104.4 & $4.54 d(7.8)$ & 103.3 & $4.73 d(7.2)$ & 103.8 & $4.70 d(7.0)$ & 103.6 & $4.78 d(8.0)$ \\
\hline $2^{\prime}$ & 74.8 & $3.41 t(7.2)$ & 74.8 & $3.39 t(7.8)$ & 74.6 & $3.38 t(7.2)$ & 74.9 & $3.39 t(7.0)$ & 74.9 & $3.54 t(8.0)$ \\
\hline $3^{\prime}$ & 77.7 & $3.43 t(7.2)$ & 77.5 & $3.43 t(8.5)$ & 77.6 & $3.41 t(8.6)$ & 77.8 & $3.41 t(8.8)$ & 75.5 & $3.67 t(9.5)$ \\
\hline $4^{\prime}$ & 71.6 & $3.38+(7.2)$ & 71.6 & $3.36 t(8.5)$ & 71.4 & $3.36 t(8.6)$ & 71.8 & $3.35 t(8.8)$ & 72.4 & $4.90 t(9.5)$ \\
\hline $5^{\prime}$ & 75.2 & $3.61 d d d(7.2,6.6,1.8)$ & 75.7 & 3.59 ddd $(8.5,6.6,1.8)$ & 75.2 & $3.66, d d d(8.6,6.3,1.8)$ & 75.6 & 3.61 ddd $(8.8,6.8,1.8)$ & 73.1 & 3.82 ddd $(9.5,9.5,5.5)$ \\
\hline $6^{\prime}$ & 64.3 & $4.49 d d(11.7,1.8)$ & 64.5 & $4.50 \mathrm{dd}(12.3,1.8)$ & 64.4 & $4.54 d d(11.7,1.8)$ & 64.8 & $4.51 d d(12.0,1.8)$ & 63.7 & $4.27 d d(12.5,5.5)$ \\
\hline & & $4.30 d d(11.7,6.6)$ & & $4.31 d d(12.3,6.6)$ & & $4.32 d d(11.7,6.3)$ & & $4.28 d d(12.0,6.8)$ & & $4.24 d d(12.5,9.5)$ \\
\hline $\mathrm{CH}_{3} \mathrm{CO}$ & & & & & & & & & 20.9 & $2.10 \mathrm{~s}$ \\
\hline $\overrightarrow{\mathrm{CH}_{3} \mathrm{CO}}$ & & & & & & & & & 172.1 & \\
\hline $1 "$ & 128.0 & & 127.7 & & 127.5 & & 127.6 & & 127.6 & \\
\hline 2" & 116.1 & $7.40 d(2.1)$ & 115.0 & $7.02 d(1.8)$ & 114.8 & $7.07 d(1.5)$ & 115.0 & $7.00 d(1.5)$ & 115.1 & $7.05 d(2.5)$ \\
\hline 3" & 148.2 & & 149.6 & & 149.3 & & 149.2 & & 149.6 & \\
\hline 4" & 145.5 & & 146.8 & & 146.5 & & 146.8 & & 146.7 & \\
\hline $5 "$ & 118.5 & $6.72 d(8.1)$ & 116.5 & $6.75 d(7.8)$ & 116.2 & $6.79 d(8.4)$ & 116.6 & $6.74 d(8.4)$ & 116.5 & $6.79 d(8.5)$ \\
\hline 6" & 125.2 & $7.08 d d(8.1,2.1)$ & 123.1 & $6.92 d d(7.8,1.8)$ & 122.9 & $6.96 d d(8.4,1.5)$ & 123.1 & $6.89 d d(8.4,1.5)$ & 123.2 & $6.93 d d(8.5,2.5)$ \\
\hline 7" & 145.5 & $6.82 d(12.9)$ & 147.2 & $7.55 d(15.9)$ & 146.9 & $7.57 d(16.0)$ & 147.2 & $7.51 d(16.0)$ & 147.3 & $7.56 d(16.0)$ \\
\hline 8" & 115.7 & $5.77 d(12.9)$ & 114.8 & $6.26 d(15.9)$ & 114.6 & $6.32 d(16.0)$ & 114.8 & $6.23 d(16.0)$ & 114.6 & $6.25 d(16.0)$ \\
\hline 9" & 168.1 & & 169.0 & & 168.8 & & 169.0 & & 168.7 & \\
\hline
\end{tabular}


Table $2{ }^{1} \mathrm{H}(500 \mathrm{MHz})$ and ${ }^{13} \mathrm{C}(125 \mathrm{MHz})$ NMR spectral data for compounds 6-8 measured in $\mathrm{CD}_{3} \mathrm{OD}$

\begin{tabular}{|c|c|c|c|c|c|c|}
\hline & \multicolumn{2}{|c|}{6} & \multicolumn{2}{|c|}{7} & \multicolumn{2}{|c|}{8} \\
\hline Position & $\delta_{\mathrm{C}}$ & $\delta_{\mathrm{H}}(J$ in $\mathrm{Hz})$ & $\delta_{\mathrm{C}}$ & $\delta_{\mathrm{H}}(J$ in $\mathrm{Hz})$ & $\delta_{\mathrm{C}}$ & $\delta_{\mathrm{H}}(J$ in $\mathrm{Hz})$ \\
\hline 1 & 127.5 & & 127.4 & & 132.1 & \\
\hline 2 & 114.0 & $6.84 d(2.5)$ & 114.0 & $6.83 d(2.0)$ & 116.4 & $6.41 d(2.0)$ \\
\hline 3 & 146.6 & & 146.8 & & 145.7 & \\
\hline 4 & 146.6 & & 146.6 & & 144.7 & \\
\hline 5 & 116.5 & $6.77 d(8.5)$ & 116.5 & $6.76 d(8.5)$ & 116.0 & $6.54 d(8.0)$ \\
\hline 6 & 118.9 & $6.74 d d(8.5,2.5)$ & 118.9 & $6.75 d d(8.5,2.0)$ & 120.6 & $6.32 d d(8.0,2.0)$ \\
\hline 7 & 88.5 & $5.95 d(8.0)$ & 88.5 & $5.95 d(8.0)$ & 46.0 & $4.13 d d(10.0,6.0)$ \\
\hline 8 & 57.2 & $4.36 d(8.0)$ & 57.1 & $4.34 d(8.0)$ & 45.3 & $3.75 d d(10.0,6.0)$ \\
\hline 9 & 172.2 & & 172.1 & & 174.5 & \\
\hline $1 "$ & 152.3 & & 152.3 & & $152.3^{\mathrm{a}}$ & \\
\hline $2^{\prime \prime}$ & 119.7 & $6.94 d(9.5)$ & 120.3 & $6.92 d(9.0)$ & $119.6^{b}$ & $6.95 d(9.0)^{\mathrm{a}}$ \\
\hline $3 "$ & 116.8 & $6.65 d(9.5)$ & 116.7 & $6.64 d(9.0)$ & $116.8^{\mathrm{c}}$ & $6.69 d(9.0)^{b}$ \\
\hline $4 "$ & 153.9 & & 154.1 & & $153.8^{\mathrm{d}}$ & \\
\hline $5^{\prime \prime}$ & 116.8 & $6.65 d(9.5)$ & 116.7 & $6.64 d(9.0)$ & $116.8^{\mathrm{c}}$ & $6.69 d(9.0)^{\mathrm{b}}$ \\
\hline 6" & 119.7 & $6.94 d(9.5)$ & 120.3 & $6.92 d(9.0)$ & $119.6^{b}$ & $6.95 d(9.0)^{\mathrm{a}}$ \\
\hline 1"-O-Glc-1"' & 103.8 & $4.76 d(7.5)$ & 104.3 & $4.76 d(7.5)$ & $103.5^{\mathrm{e}}$ & $4.73 d(7.5)^{\mathrm{c}}$ \\
\hline $2^{\prime \prime \prime}$ & 74.9 & $3.40-3.50 *$ & 75.0 & $3.40-3.50 *$ & 74.9 & $3.36-3.40 *$ \\
\hline $3^{\prime \prime \prime}$ & 77.9 & $3.40-3.50 *$ & 77.9 & $3.40-3.50 *$ & $77.8^{\mathrm{f}}$ & $3.43 * *$ \\
\hline $4 " '$ & 71.7 & $3.40-3.50 *$ & 71.8 & $3.40-3.50 *$ & 71.6 & $3.36-3.40 *$ \\
\hline $5 " '$ & 75.4 & $3.64 * *$ & 75.4 & $3.62 * *$ & 75.3 & 3.56 ddd $(7.0,6.5,2.0)$ \\
\hline $6^{\prime \prime \prime}$ & 65.7 & $4.59 d d(12.0,2.0)$ & 65.4 & $4.60 d d(12.0,2.0)$ & 65.4 & $4.47 d d(12.0,2.0)$ \\
\hline & & $4.37 d d(12.0,6.0)$ & & $4.37 d d(12.0,6.0)$ & & $4.25 d d(12.0,6.5)$ \\
\hline $1^{\prime}$ & 129.9 & & 129.9 & & 132.0 & \\
\hline $2^{\prime}$ & 117.4 & $7.01 d(2.0)$ & 117.0 & $7.03 d(1.5)$ & 116.4 & $6.40 d(2.0)$ \\
\hline $3^{\prime}$ & 143.0 & & 143.0 & & 145.7 & \\
\hline $4^{\prime}$ & 150.7 & & 150.8 & & 144.6 & \\
\hline $5^{\prime}$ & 133.1 & & 133.0 & & 116.0 & $6.54 d(8.0)$ \\
\hline $6^{\prime}$ & 118.5 & $7.08 d(2.0)$ & 118.9 & $7.14 d(1.5)$ & 120.6 & $6.31 d d(8.0,2.0)$ \\
\hline $7^{\prime}$ & 146.9 & $7.50 d(16.0)$ & 146.9 & $7.58 d(16.0)$ & 45.9 & $4.10 d d(10.0,6.0)$ \\
\hline $8^{\prime}$ & 116.0 & $6.25 d(16.0)$ & 116.0 & $6.30 d(16.0)$ & 44.7 & $3.79 d d(10.0,6.0)$ \\
\hline $9^{\prime}$ & 168.9 & & 168.8 & & 174.4 & \\
\hline $1^{\prime \prime \prime \prime}$ & 152.1 & & 152.2 & & $152.2^{\mathrm{a}}$ & \\
\hline $2^{\prime \prime \prime \prime}$ & 119.3 & $6.92 d(9.5)$ & 119.6 & $6.92 d(9.0)$ & $119.5^{b}$ & $6.91 d(9.0)^{\mathrm{a}}$ \\
\hline $3^{\prime \prime \prime \prime}$ & 116.7 & $6.61 d(9.5)$ & 116.7 & $6.61 d(9.0)$ & $116.7^{\mathrm{c}}$ & $6.67 d(9.0)^{b}$ \\
\hline $4 " '+$ & 153.7 & & 153.8 & & $153.8^{\mathrm{d}}$ & \\
\hline $5^{\prime \prime \prime}$ & 116.7 & $6.61 d(9.5)$ & 116.7 & $6.61 d(9.0)$ & $116.7^{\mathrm{c}}$ & $6.67 d(9.0)^{\mathrm{b}}$ \\
\hline 6"'" & 119.3 & $6.92 d(9.5)$ & 119.6 & $6.92 d(9.0)$ & $119.5^{b}$ & $6.91 d(9.0)^{\mathrm{a}}$ \\
\hline 1"'--O-Glc-1"'"' & 103.3 & $4.72 d(7.5)$ & 103.3 & $4.71 d(7.5)$ & $103.4^{\mathrm{e}}$ & $4.71 d(7.5)^{\mathrm{c}}$ \\
\hline $2^{2 " ' "}$ & 74.8 & $3.40-3.50 *$ & 74.9 & $3.40-3.50 *$ & 74.9 & $3.36-3.40 *$ \\
\hline $3^{\prime \prime " '}$ & 77.8 & $3.40-3.50 *$ & 77.8 & $3.40-3.50 *$ & $77.7^{\mathrm{f}}$ & $3.43 * *$ \\
\hline 4"'"' & 71.6 & $3.40-3.50 *$ & 71.4 & $3.40-3.50 *$ & 71.5 & $3.36-3.40 *$ \\
\hline $5^{\prime \prime \prime \prime}$ & 75.2 & $3.64 * *$ & 75.1 & $3.62 * *$ & 75.2 & 3.53 ddd $(7.0,6.5,2.0)$ \\
\hline $6^{\prime \prime \prime \prime}$ & 64.6 & $4.50 d d(12.0,2.0)$ & 64.6 & $4.49 d d(12.0,2.0)$ & 65.2 & $4.54 d d(12.0,2.0)$ \\
\hline & & $4.34 d d(12.0,6.0)$ & & $4.35 d d(12.0,6.0)$ & & $4.18 d d(12.0,6.5)$ \\
\hline
\end{tabular}

***, overlapped signals in the same column, multiplicity could not be resolved.

a-h, a-c , interchangeable values in each vertical column. 